\title{
Pharmacological and nonpharmacological interventions to improve symptom control, functional exercise capacity and quality of life in interstitial lung disease: an evidence synthesis
}

\author{
Sabrina Bajwah (1) ${ }^{1}$, Jill Colquitt ${ }^{2}$, Emma Loveman (102 ${ }^{2}$, Claudia Bausewein ${ }^{3}$, \\ Howard Almond ${ }^{4}$, Adejoke Oluyase (1) ${ }^{1}$, Mendy Dzingina ${ }^{1}$, Matthew Maddocks ${ }^{1}$, \\ Irene J. Higginson (10 ${ }^{1}$ and Athol Wells ${ }^{5}$
}

Affiliations: ${ }^{1}$ Cicely Saunders Institute, Dept of Palliative Care Policy and Rehabilitation, King's College London, London, UK. ${ }^{2}$ Effective Evidence LLP, London, UK. ${ }^{3}$ University of Munich, Munich, Germany. ${ }^{4}$ Action for Pulmonary Fibrosis, London, UK. ${ }^{5}$ Royal Brompton Hospital, London, UK.

Correspondence: Sabrina Bajwah, Cicely Saunders Institute, Dept of Palliative Care Policy and Rehabilitation, King's College London, Bessemer Road, London SE5 9PJ, UK. E-mail: sabrina.bajwahlakcl.ac.uk

ABSTRACT We assessed efficacy and effectiveness of pharmacological and nonpharmacological interventions in improving symptom control, functional exercise capacity and quality of life (QoL) in people living with fibrotic interstitial lung disease (ILD).

We summarised evidence from three previous reviews (to June 2014) and conducted an updated search of nine databases and grey literature (2011-2019) (registration: CRD42017065933) for prospective studies of interventions aimed to alleviate symptoms, improve QoL or functional exercise capacity in fibrotic ILD. Data were synthesised through narrative synthesis or meta-analysed as appropriate.

Forty-seven studies with 2527 participants were included. From 22 pharmacological studies of 11 different interventions $(n=1683)$, the most tested interventions were bosentan and sildenafil. From 25 nonpharmacological studies, the most tested intervention was for pulmonary rehabilitation/exercise training (PR) (22 studies, $\mathrm{n}=748$ ). There was an improvement in 6-min walk distance immediately following PR (six studies; $\mathrm{n}=200$, mean difference (MD) (95\% CI) $39.9 \mathrm{~m}$ (18.2 to 61.5)), but not longer term ( 3 or 6 months, four studies; $\mathrm{n}=147$, MD $5.3 \mathrm{~m}$ ( -12.9 to 23.4). Multiple, varied outcome measures were used (e.g. 37 studies assessing dyspnoea used 10 different scales with a lack of reporting of rate of deterioration in outcomes). Evidence gap mapping highlighted the most and least researched symptoms, as dyspnoea and cough, respectively.

This evidence synthesis highlights overwhelmingly that the most researched symptom is dyspnoea and the strongest evidence base is for short-term PR. The least researched symptom was cough. Research going forward must focus on prioritising and standardising meaningful outcomes and focussing interventions on neglected symptoms.

@ERSpublications

Cough is a neglected symptom in ILD. Future research must prioritise and standardise meaningful outcomes, and focus interventions on neglected symptoms while ensuring dyspnoea is prioritised as a primary end-point for future studies. https://bit.ly/2RNg9KH

Cite this article as: Bajwah S, Colquitt J, Loveman E, et al. Pharmacological and nonpharmacological interventions to improve symptom control, functional exercise capacity and quality of life in interstitial lung disease: an evidence synthesis. ERJ Open Res 2021; 7: 00107-2020 [https://doi.org/ 10.1183/23120541.00107-2020].

This article has supplementary material available from openres.ersjournals.com

Received: 28 Feb 2020 | Accepted after revision: 13 Sept 2020

Copyright $\odot$ ERS 2021. This article is open access and distributed under the terms of the Creative Commons Attribution Non-Commercial Licence 4.0 . 


\section{Introduction}

\section{Rationale}

Patients with interstitial lung disease (ILD) can live for many years, with some ILDs being responsive to treatment. However, fibrotic ILDs (such as idiopathic pulmonary fibrosis (IPF)) have a shorter disease trajectory, which can be rapidly advancing [1]. The resulting physical and psychological burden with impact on quality of life (QoL) can be substantial for both patients and carers [2]. A recent pivotal ILD position statement stressed the need to deliver early and effective palliative care and the importance of "living as well as possible" as disease advances [3]. Essential to achieving this is to improve symptom management and QoL as well as improving functional exercise capacity. Previous systematic reviews have summarised interventions to improve symptoms and QoL in ILD [4-6] (see online supplement 1 for further details). As the importance of improving the symptoms, functional exercise capacity and QoL of these patients has become increasingly recognised [7,8], there has been a surge in intervention studies. There is therefore a need to synthesise previous research with more recently published studies and highlight areas in which we may move research forward in a meaningful way.

\section{Objectives}

We aimed to synthesise relevant studies from three previous systematic reviews with more recently published studies and highlight gaps in research through an evidence gap map.

\section{Methods}

Protocol and registration

The systematic review was carried out in line with Preferred Reporting Items for Systematic Reviews and Meta-Analyses (PRISMA) guidelines and the protocol is registered on the PROSPERO database (CRD42017065933). The protocol stated that participants with a confirmed diagnosis of ILD would be included. However, after reflection within the Project Advisory Team, to limit heterogeneity, it was decided to focus on fibrotic ILDs only as they all shared the commonality of shorter disease trajectory, severity of symptoms and poor functional exercise capacity.

\section{Eligibility criteria}

We included studies recruiting participants with a confirmed clinical or pathological/radiological diagnosis of a fibrotic ILD (including, but not restricted to IPF and nonspecific interstitial pneumonia). We excluded studies in people with connective tissue ILDs or obstructive sleep apnoea and those for which the breakdown of ILD diagnoses was not available. Eligible interventions were any pharmacological or nonpharmacological intervention aimed at managing symptoms or improving QoL (such as oxygen therapy, opioids, corticosteroids and noninvasive ventilation) or functional exercise capacity (as measured by 6 -min walk distance (6MWD)). Radical disease modifying interventions, that were evaluated in studies primarily focused on improving survival and lung function, were deemed out of scope. We accepted any comparators/controls. Eligible outcomes were all symptom control outcomes (such as breathlessness, cough and fatigue), QoL outcomes and 6MWD. Prospective efficacy and effectiveness studies of any design were eligible including observational (e.g. cohort studies) and interventional prospective studies (e.g. randomised controlled studies, controlled clinical trials, before-and-after studies).

\section{Information sources}

Two authors (AO and SB) independently screened studies that were included in the previous reviews [4-6] for inclusion. In addition, nine electronic databases were searched for journal articles, meeting abstracts, ongoing studies and reviews from 2011 to January 2019 with no language restrictions: Ovid MEDLINE, Ovid Embase, Web of Science Core Collection, Cochrane Library, Centre for Reviews and Dissemination (CRD) databases, National Institutes of Health (NIH) ClinicalTrials.gov, World Health Organization International Clinical Trials Registry Platform (ICTRP), UK Clinical Trials Gateway and PROSPERO.

Reference lists of included studies were screened and experts in the field contacted to identify additional studies. Searches of grey literature, conference proceedings and research in progress databases were also conducted.

\section{Search}

A combination of MeSH headings and keywords were used. For example in MEDLINE, the following terms were combined: Lung Diseases, Interstitial/dt, pc, rh, su [Drug Therapy, Prevention \& Control, Rehabilitation, Surgery] OR Idiopathic Pulmonary Fibrosis/dt, pc, rh, su [Drug Therapy, Prevention \& Control, Rehabilitation, Surgery] OR Idiopathic Interstitial Pneumonias/dt, pc, th [Drug Therapy, Prevention \& Control, Therapy] OR interstitial lung disease ${ }^{\star} . t w$ OR idiopathic pulmonary fibrosis.tw OR non-specific interstitial pneumonia ${ }^{*}$.tw OR idiopathic interstitial pneumonia ${ }^{*}$.tw OR cryptogenic organi ${ }^{\star}$ 
pneumonia*.tw NOT (comment or letter or editorial).pt. The searches were then limited to 2011 to current year. The full search strategy can be found in online supplement 1 .

\section{Study selection and data collection process}

Studies were selected for inclusion in a two-stage process using predefined criteria. The full literature search results were screened independently by at least two reviewers (JC, EL, AO and SB) in order to identify all citations that potentially met the inclusion criteria, following which the full manuscripts of all selected citations were retrieved and assessed, again by two reviewers, against the inclusion criteria. Studies published as abstracts or conference presentations were only included if there were wsufficient details to allow an appraisal of the methodology and an assessment of the results. Study authors were contacted for missing information and authors of the abstracts published after 2015 were contacted if there were insufficient details to allow its inclusion in the review. Where authors did not respond, only abstracts with enough details of study participants, intervention and results were included. Where studies included a proportion of ineligible lung diseases, or where diagnoses were unclear, we contacted the authors for further information and only included these studies if this information became available. A list of potentially relevant but excluded studies is provided in online supplement 2. An inclusion flow chart and data extraction sheet were developed and used for each paper assessed. All data extraction was conducted independently by at least two reviewers. Disagreements were resolved by consensus or, if necessary, through arbitration by a third reviewer.

\section{Data items}

Data extracted included authors, intervention, comparator, diagnostic criteria, study design, quality rating and summary of results.

\section{Risk of bias in individual studies}

In assessing study quality, we used the Cochrane risk of bias tool [9] for randomised controlled trials (RCTs) and controlled clinical trials (CCTs), with the risk of selection bias used to establish the overall risk of bias for each study. We used tools developed by the NIH National Heart, Lung and Blood Institute (NHLBI) to assess the quality of other prospective studies, including cohort studies [10].

\section{Summary measures, synthesis of results and analysis}

Studies were synthesised through a narrative synthesis, with tabulation of the results of included studies. Data were combined using Review Manager (RevMan, version 5.3) [11].

Studies were examined for clinical, methodological and statistical heterogeneity. Only if sufficient homogeneity existed, was meta-analysis considered appropriate. If data permitted meta-analysis, we assessed statistical heterogeneity of the pooled effect size using the $\mathrm{I}^{2}$ statistic, the Chi-squared test for heterogeneity, and through a visual inspection of forest plots. Possible reasons for heterogeneity were explored, and fixed-effects and random-effects meta-analyses were undertaken as appropriate. The choice of model was determined by the degree of heterogeneity, as judged by the $\mathrm{I}^{2}$ statistic and $\mathrm{p}$-value for the Chi-squared test (a random-effects model was used if $\mathrm{p}<0.10$ and $/$ or $\mathrm{I}^{2}>50 \%$ ).

Dichotomous outcome data were expressed as odds ratios or risk ratios. Continuous outcome data were expressed as mean differences (MDs) or standardised mean differences (SMDs) as appropriate. For continuous variables, we considered presenting the results for end-point data or for the change from baseline. All meta-analyses were presented in forest plots, with point estimates and measures of variance (95\% confidence intervals).

\section{Results}

\section{Study selection}

The updated searches identified 18133 publications after removal of duplicates. Titles/abstracts of these publications were screened for eligibility resulting in exclusion of 17902. In total, 231 full-text articles were assessed for eligibility. Of these, 58 records (30 studies) were included in data synthesis. The reasons for exclusions of the remaining 173 articles are detailed in figure 1. Overall, 18 records (17 studies) were included from the previous reviews. In total, we included 47 primary studies reported in 76 articles (figure 1).

\section{Study characteristics and risk of bias}

A detailed summary of study characteristics is included in online supplement 3. A total of $22(46.8 \%)$ studies were RCTs, 3 (6.4\%) were CCTs, 20 (42.3\%) were before-and-after studies and 2 (4.3\%) were cohort studies. 

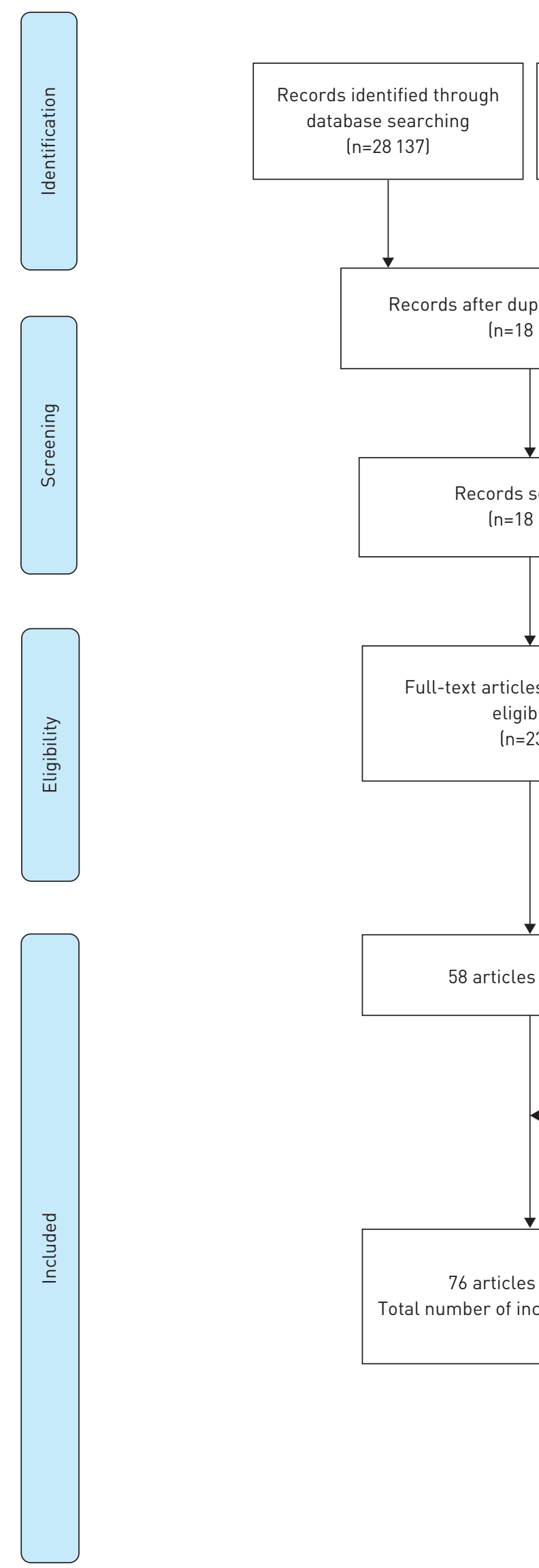

Additional records identified through other sources $(n=2)$

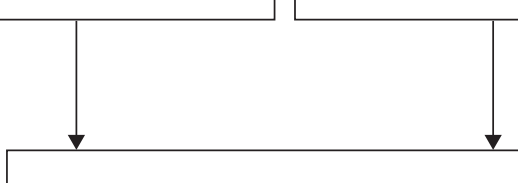

Records after duplicates removed ( $n=18$ 133)
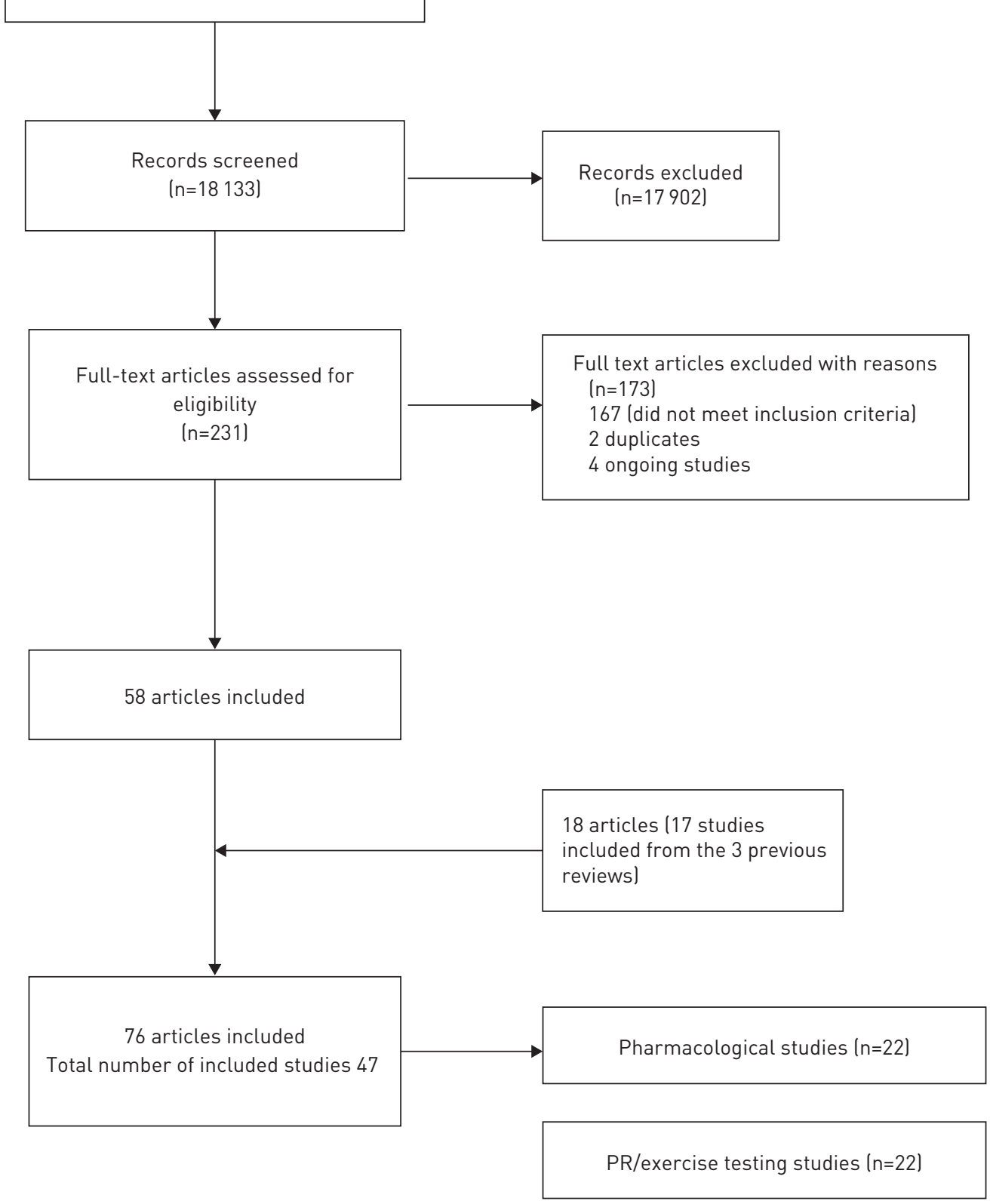

Other complex intervention studies $(n=3)$

FIGURE 1 PRISMA flow chart. PR: pulmonary rehabilitation. 
The included studies analysed 2527 participants in total, $27 \%$ to $85 \%$ were males and mean ages were from 54 to 86 years. Overall, 33 studies included only people with IPF [12-44]. Of the remaining studies, $23 \%$ to $85 \%$ had IPF and $7 \%$ to $46 \%$ had nonspecific interstitial pneumonia (NSIP) (where reported). The mean percentage predicted forced vital capacity ranged from $49.8 \%-103.6 \%$, and the $6 \mathrm{MWD}$ was from 71 to 906 metres.

A total of $22(46.8 \%)$ studies assessed 11 different pharmacological interventions [12-18, 20-25, 39, 42, 43, 45-50] and 25 (53.2\%) studies assessed nonpharmacological interventions. Pulmonary rehabilitation (PR) or exercise training was evaluated in 22 studies [27-32, 34-37, 40, 41, 44, 51-59], while 3 studies used other nonpharmacological interventions [2, 26, 38].

Among 22 studies that assessed pharmacological interventions, the comparator was placebo in 10 (45.5\%) studies $[13,14,21-23,39,42,45,48,49]$, while in $3(13.6 \%)$ studies the comparator was another treatment $[17,25,43]$. In six $(27.3 \%)$ studies, there was no control group [12, 15, 18, 20, 24, 46], while one (4.5\%) study had a healthy control group [16]. One study that assessed pharmacological interventions had room air as the control [47], while another study had "no oxygen" as control [50].

Three studies compared nonpharmacological complex interventions with usual care [2, 26, 38]. Among 22 studies that assessed PR or exercise training, one study compared PR in participants with IPF to PR in those with other ILD diagnoses [54], while another study compared PR in participants with IPF with those with sarcoidosis [31]. One study compared PR in participants with IPF with PR in those with COPD from a previous study [58]. Eleven (50\%) PR studies had no control group. Three (13.6\%) studies compared PR with usual care $[28,32,35]$, one study compared PR with a control group that did not involve PR or addition of new medicine [27], one study compared PR with a control group that did not involve any PR [59], and one study compared PR with a control group that only involved regular medical treatment [34]. Two (9.1\%) studies compared PR with another intervention [40,41].

A total of $25(53.2 \%)$ studies did not specify their primary outcome; 12 (25.5\%) studies used 6MWD as their primary outcome $[13,22-24,28,32,34,41,48,52,53,59] ; 4(8.5 \%)$ studies measured cough as primary outcome [21, 39, 42, 49]; 1 (2.1\%) study measured QoL as primary outcome [50] and $1(2.1 \%)$ study had both QoL and 6MWD as primary outcomes [29]; 4 (8.5\%) studies used other primary outcomes besides cough, QoL and 6MWD $[2,14,45,46]$. None of the studies examined dyspnoea as their primary outcome.

Table 1 presents study characteristics (study size; population, intervention, comparison, outcomes, study design (PICOS); and follow-up duration) with both a summary of risk of bias and outcomes. Online supplement 3 describes detailed PICOS characteristics of included studies, supplement 4 provides detailed baseline characteristics of included participants, while supplement 5 presents a more detailed account of their quality assessment.

\section{Main findings}

Detailed results are available in online supplement 6 with a summary of the main findings presented here.

\section{Pharmacological interventions}

Bosentan

Bosentan was assessed in three RCTs (reported in five papers $[13,14,45,60,61]$ ) and 808 participants: BUILD $1[13,61]$ showed no benefit of bosentan orally twice daily $(62.5 \mathrm{mg}$ up-titrated to $125 \mathrm{mg}$ twice daily after 1 month) compared with placebo for 6MWD or dyspnoea in 154 participants followed-up to 12 months. These findings were supported by a second larger RCT (BUILD 3) with 616 participants [14]. BUILD 1 [13] found no difference for any domain of the St George's Respiratory Questionnaire (SGRQ) at 12 months, $42 \%$ of bosentan-treated participants had an improved 36-item Short-Form Health Survey (SF-36) health transition score compared with $28 \%$ of placebo $(\mathrm{p}=0.084)$. Subgroup analysis of participants who had undergone diagnostic biopsy, however, favoured bosentan showing a significant beneficial effect on QoL with mean total SGRQ scores favouring bosentan [61]. Significant treatment effects were observed at 12 months in the impact domain of the SGRQ (median treatment effect (MTE) -7.0, $\mathrm{p}=0.03$ ), physical functioning (MTE 9.3, p=0.04), general health (MTE=9.4, $\mathrm{p}=0.01$ ) and role emotional domains of the SF-36 (MTE 0, p=0.04) [13]. However, none of these findings were supported in the larger BUILD 3 study [14]. A third RCT reported in two papers $[45,60]$ in 39 participants receiving similar doses of bosentan or placebo for 16 weeks, found no statistically significant difference in 6MWD or QoL.

\section{Sildenafil}

In the review by BAJWAH et al. [4], sildenafil was assessed in four studies (one before-and-after study [24] and two RCTs $[22,23]$, of which one of the RCTs [22] was followed by an open-label study) and 378 
TABLE 1 Summary of studies included and their results (previous review studies marked with a *)

First author [ref.], year $\quad \begin{gathered}\text { Disease group } \\ \text { (number of } \\ \text { participants); } \\ \text { diagnostic criteria }\end{gathered} \quad \begin{gathered}\text { Study design with } \\ \text { quality rating }\end{gathered}$

\section{Pharmacological}

Bosentan

CORTE $[45,60], 2014$

*KING [14], 2011

*KING JR [13], 2008

(BUILD 1) /RAGHU

[61], 2010 (second paper BUILD 1)

Sildenafil

*JACKSON [23], 2010

*ZISMAN [22], 2010

*Collard [24], 2007

\section{Chinese medicine}

Yu [25], 2016

Zeng [43], 2015

Riociguat

Nathan [48], 2017

HoEPER [46], 2013

Oxygen

VISCA [50, 62], 2017

SCHAEFFER [47], 2017

\section{Corticosteroids}

PAPIRIS [15], 2015

*FIORUCCI [17], 2008

*Hope-Gitl [16], 2003

Proton pump inhibitors DutTa [42], 2019

$$
\begin{aligned}
& \text { IPF, NSIP (39); ATS/ } \\
& \text { ERS 2002 } \\
& \text { IPF (615); ATS/ERS } \\
& \text { 2000 } \\
& \text { IPF (154); ATS/ERS } \\
& \text { 2000/2002 }
\end{aligned}
$$

\section{IPF (29); ATS/ERS \\ 2002 \\ IPF (180) \# \\ IPF (11); ATS/ERS}

2000

IPF (77); Chinese Thoracic Society criteria 2002 IPF (120); not reported
IPF, NSIP (147); not reported IPF (22); not reported

$$
\begin{aligned}
& \text { IPF (76); not } \\
& \text { reported } \\
& \text { IPF (11); not } \\
& \text { reported }
\end{aligned}
$$

\section{IPF (24); ATS/ERS 2011 IPF (30); ATS/ ERS2000/2002}
IPF (6); ATS/ERS 2002

IPF (40)"

$\begin{array}{cc}\text { RCT, unclear RoB } & \text { Placebo } \\ \text { RCT, low RoB } & \text { Placebo } \\ \text { RCT, unclear RoB } & \text { Placebo }\end{array}$

$\mathrm{RCT}$, unclear RoB

$\mathrm{RCT}$, unclear RoB

Before and after, fair quality

RCT, unclear RoB

RCT, unclear RoB

$\mathrm{RCT}$, unclear RoB

Before and after, fair quality

RCT (crossover), unclear RoB

RCT (crossover), unclear RoB

Cohort study, poor quality

Before and after, fair quality

CCT, high RoB

RCT, low RoB
Jinshuibao capsules

Foot bath group: traditional Chinese and Western medicine treatment group: traditional Chinese medicine foot bath group: combined group

\section{Placebo}

No control

No oxygen

Room air

No control

3 arms: prednisone, prednisone +cyclophosphamide, prednisone+colchicine Healthy control group

Placebo
No effect on 6MWD, dyspnoea or QoL observed. Some benefits on QoL were noted in BUILD-1 in subgroup with biopsies but these were not supported by the larger BUILD-3 study.

Improvement in 6MWD was observed in the uncontrolled study but this was not supported by data from the RCTs. One RCT found less deterioration in dyspnoea but this was not supported by meta-analysis. QoL scores were better preserved in the sildenafil group in one RCT.

Improvement in dyspnoea but no change in 6MWD with Feiwei granules. The second RCT found improvement in anxiety and depression in the combined group compared to other groups.

No significant improvement in 6MWD with riociguat.

One RCT found improvement in health status total score, dyspnoea and chest symptoms. By contrast, the second RCT found no improvement in dyspnoea but numbers were small.

Improvement in cough reflex sensitivity to capsaicin reported in one study. Another study found some improvement in dyspnoea in the prednisolone groups but numbers were small.

The RCT found a reduction in geometric mean cough frequency, daytime and night-time cough frequency, while no significant effect was observed on 24-h cough count in the before and after study. 
TABLE 1 Continued

\section{First author [ref.], year \\ Disease group \\ Inumber of \\ participants); diagnostic criteria}

KILDUFF [20], $2014 \quad$ IPF (14); ATS/ERS
2002

Thalidomide

*HoRTon [39], 2012

*Horton [12], 2008

PA 101

BIRRING [19, 49], 2016

VRP 700

SATIA [21], 2014

Opioids

*AlLeN [18], 2005

\section{Nonpharmacological}

Pulmonary

rehabilitation/exercise

testing

Chehere $[55,63], 2019$

NoLAN [44], 2018

Del Castillo [54], 2017

DoWMAn $[28,64-66]$, 2017

Nolan [56], 2017

$J_{\text {AROSCH }}[32,67,68]$, 2016

KEYSER [57, 69], 2015

RASTOGI [51], 2015

StrookAPPE [31], 2015

ARIZono [27], 2014

JACKSON [59, 70], 2014/

GAUNAURD [33, 71, 72], 2014

RIFAAT [30, 73], 2014

RYERSON [53, 74-76], 2014

VAINSHELBOIM

[34, 77-82], 2014

Holland [52, 83], 2012

IPF (23); HRCT or demonstrating UIP IPF (11); ATS/ERS 2000

IPF (23); MDT consensus

\section{IPF (20); not reported}

IPF (11); ATS/ERS

IPF and NSIP (19); ATS/ERS 2002, 2013

IPF (90); not reported

IPF (61); ATS/ERS 2011

IPF (67), NSIP (14); not reported IPF (51); not reported

IPF and NSIP (13); not reported

IPF and NSIP (22); not reported IPF (12); ATS/ERS 1999, 2013

IPF (48); ATS/ERS 2002

IPF (21); ATS/ERS 2011

\section{IPF (30); ATS/ERS} 2011

IPF and NSIP (35); not reported IPF (32); ATS/ERS 2011

IPF (25); ATS/ERS surgical lung biopsy
Before and after, fair quality

\section{Study design with quality rating}

Before and after, fair quality

RCT (crossover) $\quad$ Placebo
low RoB

Before and after, fair quality

RCT (crossover), unclear RoB
RCT (crossover),

$$
\text { unclear RoB }
$$

Placebo

No control

Placebo

IPF (9); not reported 2000
Before and after, fair quality

Before and after, poor quality

Before and after, poor quality $R C T$, low RoB

Before and after, poor quality $R C T$, low RoB

Before and after, fair quality

Before and after, fair quality

Before and after, fair quality

Prospective cohort study, poor quality $\mathrm{RCT}$, unclear RoB

Before and after, fair quality

Before and after, fair quality

$R C T$, unclear RoB

Before and after, good quality
No control

No control

Other ILD besides IPF

Usual care

No control

Usual care

No control

No control

Sarcoidosis group

Without PR or addition of new medicine Without PR

No control

No control

Regular medical treatment alone No control
Improvement in cough frequency but not nocturnal cough, cough-specific QoL and KBILD total score.

Significantly increased cough frequency within $4 \mathrm{~h}$ of treatment. However, there was also significant reduction in dyspnoea severity at $24 \mathrm{~h}$.

Improvement in dyspnoea and anxiety following s.c. administered diamorphine. However, the numbers were small.

6MWD improved immediately following the intervention but not at longer-term follow-up. Data on dyspnoea and QoL were mixed. 
TABLE 1 Continued

\begin{tabular}{|c|c|c|c|c|}
\hline First author [ref.], year & $\begin{array}{l}\text { Disease group } \\
\text { (number of } \\
\text { participants); } \\
\text { diagnostic criteria }\end{array}$ & $\begin{array}{l}\text { Study design with } \\
\text { quality rating }\end{array}$ & Control & Summary of results \\
\hline $\begin{array}{l}\text { Kozu [29], } 2011 \\
\text { loverlap of } \\
\text { participants with } \\
\text { Kozu [84], 2011] }\end{array}$ & $\begin{array}{c}\text { IPF (65); ATS/ERS } \\
2000\end{array}$ & $\begin{array}{l}\text { Before and after, } \\
\text { fair quality }\end{array}$ & No control & \\
\hline *Ozalevli [36], 2010 & $\begin{array}{c}\text { IPF (15); ATS/ERS } \\
2000\end{array}$ & $\begin{array}{l}\text { Before and after, } \\
\text { fair quality }\end{array}$ & No control & \\
\hline *RammaeRt [37], 2009 & $\begin{array}{c}\text { IPF (13); IPF; ATS/ } \\
\text { ERS } 2000\end{array}$ & $\begin{array}{l}\text { Before and after, } \\
\text { fair quality }\end{array}$ & No control & \\
\hline *Holland [41] $]^{+}, 2008$ & $\begin{array}{c}\text { IPF (34); ATS/ERS } \\
2000\end{array}$ & RCT, low RoB & Telephone support & \\
\hline *NISHIYAMA [35], 2008 & $\begin{array}{c}\text { IPF (28); ATS/ERS } \\
2002\end{array}$ & RCT, low RoB & Usual care & \\
\hline \multicolumn{5}{|l|}{ Case conference } \\
\hline BAJWAH [2], 2015 & $\begin{array}{c}\text { IPF, NSIP (47); ATS/ } \\
\text { ERS } 2000\end{array}$ & RCT, low RoB & Usual care & $\begin{array}{l}\text { Improvement in palliative care outcomes, } \\
\text { QoL and anxiety and depression scores. } \\
\text { Qualitative findings supported these data. }\end{array}$ \\
\hline \multicolumn{5}{|l|}{ Disease Management } \\
\hline *LINDELL [38], 2010 & $\begin{array}{l}\text { IPF (19); not } \\
\text { reported }\end{array}$ & RCT unclear RoB & Usual care group & $\begin{array}{l}\text { Quantitative analysis suggested the } \\
\text { intervention negatively affected } \\
\text { perceptions of physical QoL. Qualitative } \\
\text { analysis found participants valued the } \\
\text { intervention and did not feel isolated. }\end{array}$ \\
\hline
\end{tabular}

In assessing study quality, we used the Cochrane RoB tool for RCTs and CCTs, with the risk of selection bias li.e. random sequence generation and allocation concealment) used to establish the overall risk of bias for each study. Where both random sequence generation and allocation concealment were rated low, the study was given a "low" RoB; where either random sequence generation or allocation concealment was rated unclear, the study was given an unclear RoB; where both random sequence generation and allocation concealment were rated high, the study was given a "high" RoB. Other prospective studies were rated as "good", "fair", or "poor" quality depending on the number of items rated positively. For before-and-after studies, where three items or fewer were rated positively, a rating of "poor" was given; where four to seven items were rated positively, a rating of "fair" was given; where eight items or more were rated positively, a rating of "good" was given. For cross-sectional studies, where six items or fewer were rated positively, a rating of "poor" was given. IPF: idiopathic pulmonary fibrosis; NSIP: nonspecific interstitial pneumonia; ATS/ERS: American Thoracic Society/European Respiratory Society; HRCT: high-resolution computed tomography; UIP: usual interstitial pneumonia; MDT: multidisciplinary team; RCT: randomised controlled trial; RoB: risk of selection bias; CCT: controlled clinical trial; ILD: interstitial lung disease; PR: pulmonary rehabilitation; 6MWD: 6-min walk distance; QoL: quality of life; KBILD: King's Brief Interstitial Lung Disease Questionnaire. \#: IPF defined by consensus criteria; advanced stage defined as a diffusing capacity for carbon monoxide of $<35 \%$ of the predicted value. ": IPF considered the most likely diagnosis by the regional ILD MDT; cough; radiological features of honeycombing HRCT scanning; bi-basal inspiratory crackles on auscultation and features of a restrictive ventilatory defect $<90 \%$ predicted and/or transfer factor for carbon monoxide $<90 \%$ predicted). ${ }^{+}$: data from study author.

participants: the before-and after study [24] found a significant mean (90\% CI) improvement in 6MWD of $49.0 \mathrm{~m}$ (95\% CI 17.5 to 84.0 ) in 11 participants (receiving between 20 and $50 \mathrm{mg}$ sildenafil three times daily for 12 weeks). However, meta-analysis of data from the two RCTs [22, 23] with 209 IPF participants did not support this finding (effect size 5.25 ( $95 \% \mathrm{CI}-8.90$ to 19.40 ) $\mathrm{I}^{2}=56 \%, \mathrm{p}=0.467$ ). One RCT [22] showed less deterioration in dyspnoea in the sildenafil group (receiving $20 \mathrm{mg}$ three times daily for 12 weeks) compared to the placebo group but overall benefit was not supported by meta-analysis of data 
from Zisman et al. [22] and JACKSON et al. [23]: effect size -0.34 (95\% CI -0.82 to $0.13, \mathrm{I}^{2}=39.5 \%, \mathrm{p}=0.198$. ZISMAN et al. [22] found that SGRQ total score remained stable in the sildenafil group (receiving $20 \mathrm{mg}$ three times daily for 12 weeks), while worsening in placebo group (mean difference (95\% CI) $-4.08(-7.3$, $-0.86)$ ). The SF-36 general health subscore was better preserved in the sildenafil group than placebo (MD (95\% CI) $2.86(0.76,4.95))$. This was not seen during the 12 -week open-label phase.

\section{Traditional Chinese medicine}

Traditional Chinese medicine (TCM) was assessed in two RCTs [25, 43] and 197 participants: one RCT [25] assessed the therapeutic effects of Feiwei granules in 77 participants. The intervention group $(n=62)$ received Feiwei granules twice a day for 6 months, while the control group $(n=15)$ received Jinshuibao capsules, also a TCM. Participants were followed-up for 6 months. Dyspnoea and SGRQ total score were significantly worse in the Feiwei granules group at baseline, and between-group change in dyspnoea scores from baseline to 3 months was not significant (TCM group MD (SD) $-0.6(0.7)$, control group MD (SD) $-0.3(0.7) ; \mathrm{p}=0.111)$. However, between-group change in dyspnoea scores from baseline to 6 months (TCM group MD (SD) $-0.8(0.8)$, control group MD (SD) $0.1(1.0) ; \mathrm{p}=0.001$ ) and from 3 months to 6 months (TCM group MD (SD) -0.2 (0.7), control group MD (SD) 0.3 (0.7); p=0.009) showed significant improvement in the intervention group. SGRQ total score change from baseline to 3 months also showed significant improvement (TCM group MD (SD) -8 (14), control group MD (sD) -1 (6); $\mathrm{p}=0.011$ ). There was no difference in change in 6MWD from baseline to 3 months (TCM group MD (SD) 17 (124), control group MD (SD) 19 (38); p>0.05), baseline to 6 months (TCM group MD (SD) 48 (107), control group $\mathrm{MD}(\mathrm{SD}) 30$ (54); $>>0.05$ ) and from 3 months to 6 months (TCM group MD (SD) 31 (82), control group MD (sD) 11 (41); p>0.05). The other RCT [43] evaluated the impact of TCM foot bath combined with traditional Chinese and Western medicine nursing in 120 participants. ZENG et al. 2015 [43] randomly assigned participants to four groups. There was significant improvement in anxiety and depression of participants in the combined group (traditional Chinese and Western medicine nursing+TCM foot bath) compared to individual treatments at 6 months $(\mathrm{p}<0.05)$.

\section{Riociguat}

Riociguat was assessed in one RCT [48] and one before-and-after [46] study and 169 participants: HoEPER et al. [46] carried out a small study involving 22 participants and found a nonsignificant increase in 6MWD (difference (SD): 25 (64), 95\% CI -8 to 58) at 12 weeks in those receiving riociguat three times daily. Authors stated that no significant changes compared with baseline were seen for other relevant outcomes but no data were presented. NATHAN et al. [48] conducted an RCT involving 147 participants receiving either riociguat three times daily for 26 weeks or placebo. No significant improvement was noted in 6MWD for the intervention group at 26 weeks (MD $21 \mathrm{~m}, 95 \% \mathrm{CI}:-9$ to $52 ; \mathrm{p}>0.2$ ).

\section{Ambulatory oxygen}

Oxygen was assessed in two studies (both crossover RCTs) and 87 participants: VISCA et al. [50, 62] compared 2 weeks of ambulatory oxygen to no ambulatory oxygen in 76 participants with fibrotic ILD. Health status measured by the King's Brief Interstitial Lung Disease (KBILD) questionnaire was significantly improved in the intervention group for the total score (MD 3.7; 95\% CI 1.8, 5.6; $<<0.0001$ ), breathlessness and activity domain (MD: 8.6; 95\% CI 4.7, 12.5; p<0.0001) and chest symptoms (MD: 7.6; 95\% CI 1.9, 13.2; $\mathrm{p}=0.009$ ) but not for psychological symptoms. Significant improvements were also seen on the University of California San Diego (UCSD) shortness of breath (SOB) questionnaire $(\mathrm{p}<0.0001)$ and SGRQ total score $(\mathrm{p}=0.018)$; SCHAEFFER et al. [47] compared oxygen with room air (duration and length of follow-up not reported) in 20 enrolled participants (11 with IPF), and did not find any significant difference in dyspnoea. However, it is unclear how many participants were included in analysis.

\section{Corticosteroids}

Corticosteroids were assessed in three nonrandomised studies [15-17] and 60 participants. Hope-GiLl et al. [16] conducted a small open-label study of prednisolone $\left(40-60 \mathrm{mg} \cdot \mathrm{day}^{-1}\right.$ for at least 4 weeks) in six participants with capsaicin-induced cough and found a significant reduction in mean (SE) visual analogue scale (VAS) score from $7.2(0.8)$ to $2.2(2.5)$ at 4 weeks $(\mathrm{p}<0.05)$. Fiorucci et al. [17] conducted a three-arm before-and-after study of 30 participants receiving prednisolone alone (group 1), prednisolone and cyclophosphamide (group 2) and prednisolone and colchicine (group 3) for 18 months. There were significant improvements in dyspnoea in the prednisolone and colchicine group compared to the other two groups. Baseline dyspnoea mean (SD) was 8.4 (2.5) versus 18 months 6.3 (2.2) ( $\mathrm{p}=0.001$ ). Two participants of group 1 (18\%), one patient of group $2(11 \%)$ and eight participants of group $3(80 \%)$ showed a significant decrease in dyspnoea $(\mathrm{p}=0.001)$. PAPIRIs et al. [15] conducted a cohort study of 24 participants and found no difference in 6MWD between participants with an acute exacerbation of IPF "ever treated" and "never treated" with steroids. The follow-up duration was not stated. 


\section{Proton pump inhibitor therapy}

Proton pump inhibitor therapy was assessed in two studies (one RCT [42] and one before-and-after study [20]) and 68 participants: the before-and-after study [20] assessed the effects of omeprazole $40 \mathrm{mg}$ twice daily or lansoprazole $30 \mathrm{mg}$ twice daily, plus ranitidine $300 \mathrm{mg}$ at night for 8 weeks in 14 participants. The median 24-h cough count showed a nonsignificant increase from baseline $(p=0.7)$. The matched placebo RCT assessed the effects of $20 \mathrm{mg}$ omeprazole twice daily in 40 participants. This study found that geometric mean cough frequency at the end of treatment, adjusted for baseline, was $39.1 \%$ lower (95\% CI $66 \%$ lower to $9.3 \%$ higher) in the omeprazole group compared with placebo. Similar results were obtained for daytime and night-time cough frequency. There was no clinically meaningful difference for patient-reported symptoms of cough and reflux. There was no significant difference in change in $6 \mathrm{MWD}$.

\section{Thalidomide}

Thalidomide was assessed in two studies (an open-label prospective cohort trial and a crossover RCT [12, 39]) and 34 participants. HorTON et al. [12] presented data in 11 participants with chronic cough caused by IPF. There was a marked to complete resolution of cough in 10 participants who received thalidomide administered daily in 100-400 mg doses for 3 months. SGRQ data showed significant decrease on the cough question from baseline $4.9(0.3)$ to 2.2 (1.6) at 3 months ( $p=0.03)$. A crossover RCT of 23 participants was conducted by HoRTon et al. [39] where $50 \mathrm{mg}$ (increased to $100 \mathrm{mg}$ after 2 weeks if no improvement in cough) of thalidomide was administered orally once daily for 12 weeks in a crossover design with a 2-week washout. There was a significant improvement in cough-specific QoL MD ((95\% CI) $-11.4(-15.7$ to -7.0$) \mathrm{p}<0.001)$ for those taking thalidomide compared with placebo.

\section{PA101 (cromolyn sodium)}

PA101 was assessed in one crossover placebo-controlled RCT $[19,49]$ and 23 IPF participants. A total of $40 \mathrm{mg}$ PA101 (cromolyn sodium) was administered via a high-efficiency nebuliser three times daily for 14 days with washout for 14 days before crossover. The intervention group had significantly reduced cough frequency (ratio of least-squares means $0.67,95 \%$ CI $0.48,0.94 ; \mathrm{p}=0.0241$ ) but nocturnal cough, cough-specific QoL and KBILD total score were not significantly improved.

\section{VRP700}

VRP700 was assessed in one crossover placebo RCT [21] and 20 participants. Participants with cough received either a single inhaled dose of VRP700 $(100 \mathrm{mg})$ or placebo as a single dose intervention with a 7-day washout. VRP700 significantly increased cough frequency within $4 \mathrm{~h}$ of treatment compared with placebo (136.8 (95\% CI 80.3, 233.1) versus 64.9 (95\% CI 38.1, 110.6); $\mathrm{p}<0.001)$. Reported cough severity and urge to cough were not significantly different. The authors state that dyspnoea severity at $24 \mathrm{~h}$ was significantly better in the VRP700 group but the data were not presented.

\section{Opioids}

Opioids were assessed in one before-and-after study [18] and 11 participants: AlLEN et al. [18] administered single s.c. diamorphine doses to 11 IPF participants and showed a substantial fall in dyspnoea score from mean (SD) baseline 83 (13) to $36(11)$ at $15 \mathrm{~min}$ and $36(12)$ at $30 \mathrm{~min}(\mathrm{p}<0.001)$. The authors also reported decreased observed anxiety (no details given).

\section{Nonpharmacological interventions}

Pulmonary rehabilitation and exercise training

PR and exercise training were assessed by 22 studies (6 RCTs [28, 32, 34, 35, 41, 59], 1 controlled clinical trial [40], 1 prospective cohort study [27] and 14 before-and-after studies [29-31, 36, 37, 44, 51-58]) with 748 participants in total. Among studies assessing PR, six had participants with severe disease (diffusing capacity of the lung for carbon monoxide $\left(D_{\mathrm{LCO}}\right) \%$ pred $\left.<45\right)[31,37,40,55,57,59]$, while one study comprised a mixture of participants with severe and nonsevere disease [29].

The Cochrane Review [6] included five RCTs measuring dyspnoea and combined three of these in a meta-analysis. These were screened and relevant data were extracted. We identified five additional controlled trials with new data on dyspnoea, of which only one could be added to the three RCTs retrieved from the Cochrane meta-analysis, and one prospective cohort study; this was considered inappropriate, as a large proportion of evidence would be omitted.

The PR studies assessed dyspnoea using seven different scales. These included four unidimensional scales such as the Borg scale [86] and modifications of it, activity domain of the SGRQ [87], dyspnoea domain of the chronic respiratory disease questionnaire (CRDQ) [88] and the oxygen cost diagram [89] as well as three multidimensional scales including baseline/transition dyspnoea index (BDI/TDI) [90], the Medical Research Council (MRC) scale [91] and modifications of it, and the UCSD SOB questionnaire [92]. 
Of the seven controlled studies, three had inconsistent results from the different dyspnoea scales they used [28, 34, 41], while one study [35] found no significant improvement. The remaining three studies did not report any significant between-group difference [32, 40, 59]. Twelve before-and-after studies [29-31, 36, 37, 44, 51-56] assessed dyspnoea. One study [29] found significant differences in the magnitude of change in dyspnoea immediately after PR in participants with MRC dyspnoea grades 2,3, and 5 but not in participants with MRC dyspnoea grade 4. No significant improvement was found on longer follow-up. Five of these studies $[30,36,44,54,56]$ found a statistically significant improvement in dyspnoea immediately after the intervention but did not assess its long-term sustainability. CHeHere et al. [55] used one unidimensional (Borg scale) [86] and one multidimensional (BDI/TDI) [90] method to assess dyspnoea and found contrasting results: results from the BDI/TDI showed significant improvement while that with the Borg scale was not significant. Three other studies [31,37, 51] found no significant improvement in dyspnoea. Only two studies $[52,53]$ reported longer follow-up (6 months) with inconsistent results.

Six RCTs measured health-related QoL (HRQoL) immediately following PR [28, 32-35, 41], while four of these studies involved longer follow-up [28, 32, 33, 41]. However, meta-analysis was considered inappropriate. Overall, results were inconsistent with some RCTs finding no statistically significant improvement effect. Longer follow-up showed PR had no significant improvement effect. Ten before-and-after studies measuring HRQoL [29, 30, 36, 37, 44, 53-56, 58] showed inconsistent findings.

A statistically significant difference between PR and control was found for change in 6MWD immediately following the intervention ( $\mathrm{n}=6$ studies with 200 participants, MD $39.85 \mathrm{~m}, 95 \% \mathrm{CI} 18.17$ to $61.53, \mathrm{I}^{2} 48 \%$, random effects; figure 2). At longer-term follow-up (3 or 6 months), there was no significant difference in change in 6MWD between groups ( $\mathrm{n}=4$ studies with 147 participants, MD $5.26 \mathrm{~m}, 95 \%$ CI -12.88 to $23.40, \mathrm{I}^{2} 6 \%$, fixed effects; figure 3). 11 of the 14 before-and-after studies reported $6 \mathrm{MWD}$; most studies found improvement in 6MWD immediately following PR. Only three studies [52, 53, 84] reported longer (6-month) follow-up and results were contradictory.

\section{Case conference}

One fast-track RCT [2] evaluated the effects of a palliative care case conference in 53 participants. The intervention was a multi-professional, holistic case conference, including symptom control and developing a home-based nurse-led individualised care plan. Mean (SD) palliative care outcome scores at 4 weeks were -5.7 (7.5) fast-track versus -0.4 (8.0) control (mean change difference between the two arms was -5.3 (95\% CI -9.8, -0.7) ( $\mathrm{p}=0.02)$; effect size $(95 \% \mathrm{CI})-0.7(-1.2,-0.1)$. The secondary outcomes of QoL, anxiety and depression were superior in the intervention arm, and none was worse. Qualitative findings corroborated these data.

\section{Patient and Partner Empowerment Programme}

A controlled clinical trial $[26,85]$ evaluated the effect of a short multidisciplinary empowerment programme, Patient and Partner Empowerment Programme in 23 participants. Results showed no statistically significant change in health status, dyspnoea or HRQoL at 3 weeks and at 3 months.

\section{Disease management programme}

One RCT [38] evaluated a disease management program in 19 participants with mixed results. Quantitative analysis showed the intervention negatively affected perceptions of physical QoL and a

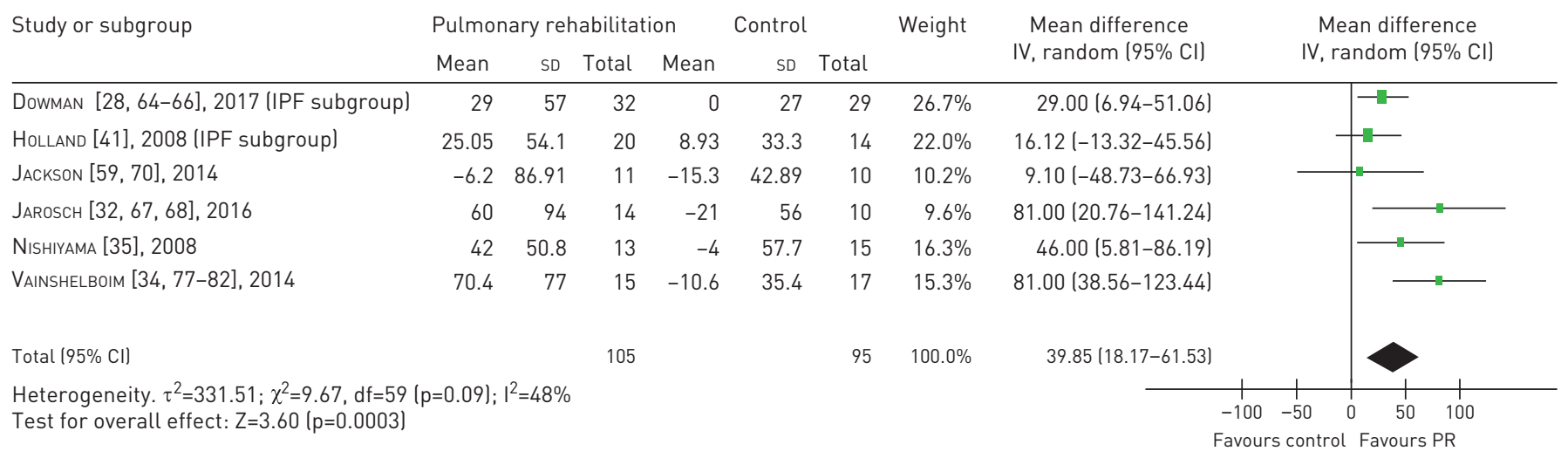

FIGURE 2 Meta-analysis of pulmonary rehabilitation (PR) versus control for 6-min walk distance at intervention end. IPF: idiopathic pulmonary fibrosis. 


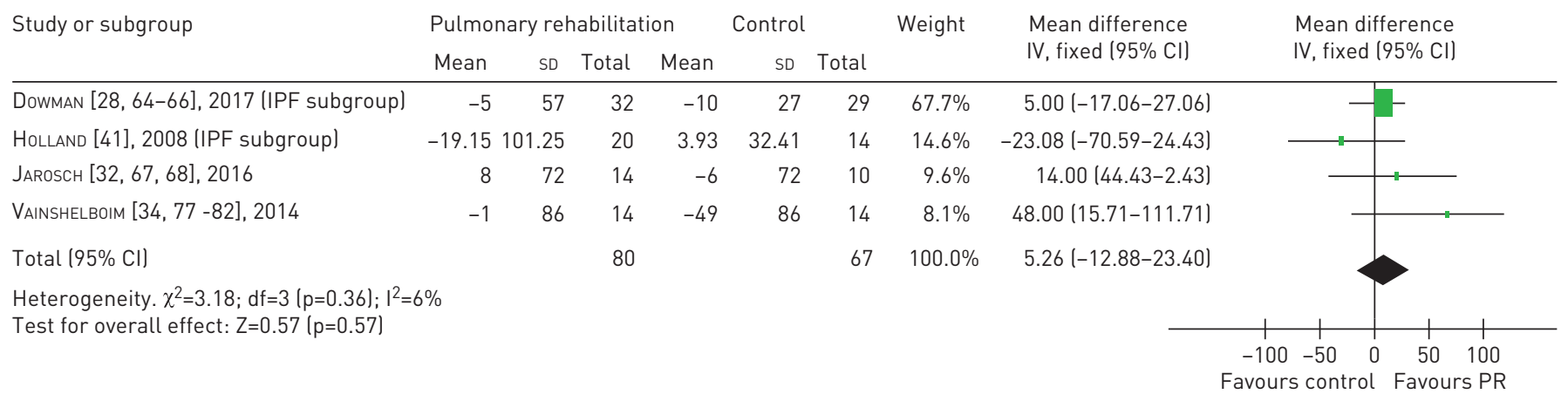

FIGURE 3 Meta-analysis of pulmonary rehabilitation (PR) versus control for 6-min walk distance at longest follow-up. IPF: idiopathic pulmonary fibrosis.

tendency for greater anxiety. The mean end Beck Anxiety Index scores for the intervention were 15.13 (6.92) and control were $8.56(6.95)(\mathrm{p}=0.077)$ reflecting a nonsignificant increase in anxiety in the intervention group. Mean (SD) end score for the SF-36 physical component showed a statistically significant difference, intervention 31.06 (4.61) versus control 36.04 (4.63) p=0.038, reflecting a negative impact on perceptions of physical HRQoL. However, qualitative analysis found participants valued the intervention and did not feel isolated.

\section{Adverse events}

Adverse events were reported in 15 studies assessing pharmacological interventions, namely, oxygen, bosentan, corticosteroids, opioids, proton pump inhibitors, PA101, riociguat, sildenafil and thalidomide $[12-15,17,22-24,39,42,45,46,62,93,94]$ (see online supplement 7 for details). In particular, seven studies described serious adverse events in studies of bosentan [13, 14, 45] sildenafil [22], thalidomide [39], riociguat [46] and oxygen [50], while three studies reported deaths in studies of corticosteroids [15], bosentan [45] and oxygen [50]. BirRING et al. [49] and Yu et al. [25] reported that there were no serious adverse events in studies of cromolyn sodium and Feiwei granules respectively. Five PR studies reported that there were either no serious adverse events $[34,57]$ or no adverse events $[29,36,41]$ at all.

\section{Discussion}

We have conducted the most comprehensive evidence synthesis to date providing up-to-date evidence on pharmacological and nonpharmacological interventions to improve symptom control, functional exercise capacity and QoL for people living with fibrotic ILD. To aid reflection on the evidence base for practitioners, policy makers and researchers, we have mapped our findings on an evidence gap map (figure 4).

\section{Pharmacological}

The most tested pharmacological interventions were bosentan and sildenafil. Data on pharmacological interventions to improve symptoms, particularly dyspnoea, continue to be limited. Of the drug studies, there were only four studies ( $\mathrm{n}=106$ participants) with a primary outcome of cough $[19,21,39,42]$, and no study with a primary outcome of dyspnoea.

Interestingly, current ILD clinical guidelines [7, 95] recommend the use of a number of pharmacological measures (including opioids and benzodiazepines) for symptomatic management of ILD despite limited evidence in this group. However, a recent important study by FAISAL et al. [96] suggests that despite very different pathological processes, ILD and COPD patients' perceptual responses (including intensity and quality) to dyspnoea are similar. In addition, there are likely to be common mechanisms of dyspnoea. Therefore, we would suggest that it is reasonable to extrapolate evidence of effectiveness of pharmacological measures that act centrally to improve dyspnoea (e.g. opioids and benzodiazepines) from COPD to ILD. However, we would recommend a word of caution; while evidence of effectiveness may be transferred, this does not mean that safety profiles of the drugs are the same in both populations, as demonstrated by analyses of opioids and benzodiazepine safety data in COPD [97] and ILD [98].

The British Thoracic Society recently endorsed the occasional use of oxygen by specialist teams when breathlessness is unresponsive to all other treatment [99]. This review shows that there is now some evidence for oxygen in improving symptoms and QoL in ILD patients who desaturate on exercise. However, it remains unclear whether oxygen is any more effective than nonpharmacological interventions such as fans or cognitive behavioural therapy. In light of the many negative psychological, social and financial aspects of oxygen, further research is needed before widescale adoption of oxygen in this group. 
FIGURE 4 Evidence gap map for interventions to improve symptoms, functional exercise capacity and quality of life in interstitial lung disease. Each shape represents a study reporting the outcome. Shape size is an indication of study size. RCT: randomised controlled trial; CCT: controlled clinical trial.

\begin{tabular}{|c|c|c|c|c|}
\hline & Dyspnoea & Cough & $\begin{array}{c}\text { Functional } \\
\text { exercise capacity }\end{array}$ & $\begin{array}{l}\text { Quality } \\
\text { of life }\end{array}$ \\
\hline \multicolumn{5}{|l|}{ Bosentan } \\
\hline \multicolumn{5}{|l|}{ Sildenafil } \\
\hline \multicolumn{5}{|l|}{ Chinese medicine } \\
\hline \multicolumn{5}{|l|}{ Riociguat } \\
\hline \multicolumn{5}{|l|}{ Oxygen } \\
\hline Corticosteroids & & 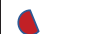 & E & \\
\hline \multicolumn{5}{|l|}{$\begin{array}{l}\text { Proton pump } \\
\text { inhibitors }\end{array}$} \\
\hline \multicolumn{5}{|l|}{ Thalidomide } \\
\hline \multicolumn{5}{|l|}{$\begin{array}{c}\text { PA } 101 \\
\text { (Cromolyn sodium) }\end{array}$} \\
\hline VRP 700 & P & $\infty$ & & \\
\hline \multicolumn{5}{|l|}{ Opioids } \\
\hline \multicolumn{5}{|l|}{ Case conference } \\
\hline \multicolumn{5}{|l|}{$\begin{array}{l}\text { Disease management } \\
\text { programme }\end{array}$} \\
\hline \multicolumn{5}{|l|}{$\begin{array}{l}\text { Patient and partner } \\
\text { empowerment } \\
\text { programme }\end{array}$} \\
\hline \multicolumn{5}{|l|}{$\begin{array}{l}\text { Pulmonary } \\
\text { rehabilitation/ } \\
\text { exercise training }\end{array}$} \\
\hline \multicolumn{5}{|c|}{ RCT with unclear risk of bias } \\
\hline \multirow{2}{*}{\multicolumn{2}{|c|}{$\begin{array}{l}\text { RCT with low risk of bias } \\
\text { CCT with high risk of bias }\end{array}$}} & Cohort s & dy of fair quality & \\
\hline & & Before a & after study of fai & quality \\
\hline
\end{tabular}

\section{Nonpharmacological}

As shown by figure 4, the most tested intervention (and for which there is the strongest evidence base) was PR, with $47 \%$ of all studies being PR-related. Studies with PR achieved short-term improvements in 6MWD. This contrasts with COPD, where a reduction in dyspnoea is more consistent [100]. The difference in effect for PR in ILD may be related to the more fluctuating and declining nature of the disease. Among studies assessing PR, six had participants with severe disease $\left(D_{\mathrm{LCO}}, \%\right.$ pred $\left.<45\right)[31,37$, $40,55,57,59]$, while one study comprised a mixture of participants with severe and nonsevere disease [29]. Participants with more advanced disease may be less able to participate in PR and therefore it is unreasonable to expect to see the improvement seen in COPD. In ILD, the more appropriate outcome is preservation in symptoms and QoL rather than improvement per se. While no clear improvement in symptoms and QoL of life is seen, a slowing of deterioration in rapidly depreciating disease or the 
attainment of individualised goals are more meaningful clinical outcomes [101]. We attempted to analyse rate of deterioration of outcomes but were unable to do so, limited by the values presented. Furthermore, a plethora of dyspnoea assessment tools limited generalisability. A total of 37 studies assessed dyspnoea using 10 different scales. Of these, 19 studies were in PR using seven different scales to measure dyspnoea. As noted by SimilowsKi AND SERRESSE [102], dyspnoea is a complex and multidimensional experience that warrants a multidimensional tool to assess the effect of complex interventions. PR may be having a positive effect on the affective dimensions of dyspnoea, which are not captured by unidimensional tools focussing on the symptom of dyspnoea alone (e.g. VAS). In contrast, multidimensional tools (e.g. CRDQ) assess the impact of dyspnoea on various domains such as activities of daily living, emotional and mental functioning, sense of mastery or other person related outcomes. Of note, for the 19 PR studies that assessed dyspnoea, 4 unidimensional and 3 multidimensional dyspnoea measures were used. A review of breathlessness tools by BAUSEWEIN et al. [103] notes that there is no one scale that can accurately reflect the far-reaching effects of breathlessness in a patient with advanced disease. They recommend combining a unidimensional scale with either a disease-specific scale or a multidimensional scale in conjunction with other methods such as qualitative methods to fully gauge psychosocial impact of interventions to improve dyspnoea. In this evidence synthesis, only seven PR studies used both unidimensional and multidimensional measures.

\section{Recommendations}

The evidence gap in figure 4 demonstrates graphically that dyspnoea is the most researched symptom and cough, the least. Research now needs to focus on pharmacological interventions to improve neglected symptoms such as cough while ensuring that dyspnoea is prioritised as a primary end-point for future studies.

The ongoing presentation of limited data and focus on improvement of outcomes is leading to discounting of the effectiveness of interventions. Given the problem of powering and the multiplicity of uncertainties listed above, an international consensus is needed on the goals of palliative interventions, the ranking of candidate primary end-points in each domain and the selection criteria for studied populations. Failure to reach such consensus may lead to similar difficulties to those in studies of acute IPF exacerbations and ILD associated with occult connective tissue disease. In both areas, lack of standardisation hindered integrating a decade of published data into an evidence base. In both areas, international consensus statements were formulated to confront fragmentation of research. Based on this review, research into palliative care in ILD is arguably in danger of following the same pathway. We call for a major initiative, starting with a Delphi exercise, to agree on an ongoing research agenda.

\section{Strengths and limitations}

Strengths of this work include a registered protocol, and a systematic and comprehensive search across multiple databases, inclusive of grey literature, with no exclusions by publication year. All screening, eligibility, data extraction and quality assessment was conducted independently by two authors, and multiple stakeholders (researchers, clinicians and patient representative) contributed to the analysis and interpretation of these data. In addition, we have for the first time, clearly mapped the evidence gap to provide a visual overview of the evidence gap for types of interventions evaluated and outcomes reported. This allows the reader to explore findings and quality of the existing evidence and facilitate informed judgement and evidence-based decision-making. Importantly, the evidence gap map has identified key areas where little or no evidence from research is available and where future research can be focused.

The main limitation of this review is the low quality of the studies included. Many studies were uncontrolled, with small sample sizes and unclear quality aspects. Follow-up was often short and few interventions provided evidence that could be meta-analysed. However, we have only used high-quality studies in the meta-analyses and presented studies clearly to allow readers to draw their own conclusions. To limit heterogeneity, we did not include connective tissue disease-associated ILDs and it is possible that there are further relevant studies available. In addition, we included studies looking at both efficacy and effectiveness as we thought it important to assess and present both. Moreover, although we did not assess for statistical evidence of publication bias, there was evidence of selective reporting where study authors did not provide data for statistically nonsignificant findings.

\section{Conclusion and clinical implications}

This evidence synthesis highlights overwhelmingly that the most researched symptom is dyspnoea and the strongest evidence base is for short-term PR. The least researched symptom was cough. The research priorities going forward must focus on prioritising and standardising meaningful outcomes and focussing interventions on neglected symptoms. We call for a sea change in the way we conduct research in this area 
starting in the first instance with a Delphi exercise concluding in recommendations of a core outcome measure set.

Conflict of interest: None declared.

Support statement: This paper presents independent research funded by the National Institute for Health Research (NIHR) under its Research for Patient Benefit Programme (grant reference no. PB-PG-0815-20030). The views expressed are those of the authors and not necessarily those of the National Health Service, the NIHR or the Dept of Health and Social Care. Funding information for this article has been deposited with the Crossref Funder Registry.

\section{References}

1 Vancheri C. Idiopathic pulmonary fibrosis and cancer: do they really look similar? BMC Med 2015; 13: 220-220.

2 Bajwah S, Ross JR, Wells AU, et al. Palliative care for patients with advanced fibrotic lung disease: a randomised controlled phase II and feasibility trial of a community case conference intervention. Thorax 2015; 70: 830-839.

3 Kreuter M, Bendstrup E, Russell AM, et al. Palliative care in interstitial lung disease: living well. Lancet Respir Med 2017; 5: 968-980.

4 Bajwah S, Ross JR, Peacock JL, et al. Interventions to improve symptoms and quality of life of patients with fibrotic interstitial lung disease: a systematic review of the literature. Thorax 2013; 68: 867-879.

5 Loveman E, Copley VR, Colquitt J, et al. The clinical effectiveness and cost-effectiveness of treatments for idiopathic pulmonary fibrosis: a systematic review and economic evaluation. Health Technol Assess 2015; 19: i-xxiv, 1-336.

6 Dowman L, Hill CJ, Holland AE. Pulmonary rehabilitation for interstitial lung disease. Cochrane Database Syst Rev 2014; 10: CD006322.

7 National Institute for Health and Care Excellence. Idiopathic pulmonary fibrosis in adults: diagnosis and management. Clinical Guideline (CG 163). Updated May 2017. NICE, London, 2013.

8 Raghu G, Rochwerg B, Zhang Y, et al. An Official ATS/ERS/JRS/ALAT Clinical Practice Guideline: Treatment of Idiopathic Pulmonary Fibrosis. An Update of the 2011 Clinical Practice Guideline. Am J Respir Crit Care Med 2015; 192: e3-e19.

9 Higgins JP, Altman DG, Gotzsche PC, et al. The Cochrane Collaboration's tool for assessing risk of bias in randomised trials. BMJ 2011; 343: d5928.

10 NHLBI. Study quality assessment tools 2018 www.nhlbi.nih.gov/health-topics/study-quality-assessment-tools Date last accessed: January 25, 2018. Date last updated: 12 December 2020.

11 RevMan. Version 5.3. The Nordic Cochrane Centre, The Cochrane Collaboration, 2014, Copenhagen, 2014.

12 Horton MR, Danoff SK, Lechtzin N. Thalidomide inhibits the intractable cough of idiopathic pulmonary fibrosis. Thorax 2008; 63: 749-749.

13 King TE Jr, Behr J, Brown KK, et al. BUILD-1: a randomized placebo-controlled trial of bosentan in idiopathic pulmonary fibrosis. Am J Respir Crit Care Med 2008; 177: 75-81.

14 King TE Jr, Brown KK, Raghu G, et al. BUILD-3: a randomized, controlled trial of bosentan in idiopathic pulmonary fibrosis. Am J Respir Crit Care Med 2011; 184: 92-99.

15 Papiris SA, Kagouridis K, Kolilekas L, et al. Survival in Idiopathic pulmonary fibrosis acute exacerbations: the non-steroid approach. BMC Pulm Med 2015; 15: 162.

16 Hope-Gill BD, Hilldrup S, Davies C, et al. A study of the cough reflex in idiopathic pulmonary fibrosis. Am J Respir Crit Care Med 2003; 168: 995-1002.

17 Fiorucci E, Lucantoni G, Paone G, et al. Colchicine, cyclophosphamide and prednisone in the treatment of mild-moderate idiopathic pulmonary fibrosis: comparison of three currently available therapeutic regimens. Eur Rev Med Pharmacol Sci 2008; 12: 105-111.

18 Allen S, Raut S, Woollard J, et al. Low-dose diamorphine reduces breathlessness without causing a fall in oxygen saturation in elderly patients with end-stage idiopathic pulmonary fibrosis. Palliat Med 2005; 19: 128-130.

19 Birring S, Wijsenbeek M, Al SA, et al. Significant improvement in refractory chronic cough with inhaled PA101 in patients with idiopathic pulmonary fibrosis: Results from phase 2 trial. Eur Respir J 2016; 48: Suppl. 60, OA4958.

20 Kilduff CE, Counter MJ, Thomas GA, et al. Effect of acid suppression therapy on gastroesophageal reflux and cough in idiopathic pulmonary fibrosis: an intervention study. Cough 2014; 10: 4.

21 Satia I, Badri H, Dockry R, et al. A randomised, double-blind, placebocontrolled crossover study to assess the efficacy of a single dose of $100 \mathrm{mg}$ of VRP700 by inhalation in reducing the frequency and severity of cough in adult patients with idiopathic pulmonary fibrosis. Thorax 2015; 70: A52.

22 Zisman DA, Schwarz M, Anstrom KJ, et al. A controlled trial of sildenafil in advanced idiopathic pulmonary fibrosis. N Engl J Med 2010; 363: 620-628.

23 Jackson RM, Glassberg MK, Ramos CF, et al. Sildenafil therapy and exercise tolerance in idiopathic pulmonary fibrosis. Lung 2010; 188: 115-123.

24 Collard HR, Anstrom KJ, Schwarz MI, et al. Sildenafil improves walk distance in idiopathic pulmonary fibrosis Chest 2007; 131: 897-899.

25 Yu Y, Sun Z, Shi L, et al. Effects of Feiwei granules in the treatment of idiopathic pulmonary fibrosis: a randomized and placebo-controlled trial. J Tradit Chin Med 2016; 36: 427-433.

26 van Manen MGJ, van 't Spiker A, Tak NC, et al. Patient and partner empowerment programme for idiopathic pulmonary fibrosis. Eur Respir J 2017; 49: 1601596.

27 Arizono S, Taniguchi H, Sakamoto $\mathrm{K}$, et al. Endurance time is the most responsive exercise measurement in idiopathic pulmonary fibrosis. Respir Care 2014; 59: 1108-1115.

28 Dowman LM, McDonald CF, Hill CJ, et al. The evidence of benefits of exercise training in interstitial lung disease: a randomised controlled trial. Thorax 2017; 17: 610-619.

29 Kozu R, Jenkins S, Senjyu H. Effect of disability level on response to pulmonary rehabilitation in patients with idiopathic pulmonary fibrosis. Respirology 2011; 16: 1196-1202. 
61 Raghu G, King TE Jr, Behr J, et al. Quality of life and dyspno fibrosis. Egypt J Chest Dis Tuberc 2014; 63: 1013-1017. 1872-1879. pulmonary fibrosis. Respirology 2008; 13: 394-399. pulmonary fibrosis. Multidiscip Respir Med 2010; 5: 31-37. Rev Mal Respir 2009; 26: 275-282. 2010; 39: 304-314. fibrosis: a randomized trial. Ann Intern Med 2012; 157: 398-406. with inspiratory muscle training. Pneumonol Alergol Pol 2008; 76: 131-141. exercise training in interstitial lung disease. Thorax 2008; 63: 549-554. idiopathic pulmonary fibrosis. Thorax 2019; 74: 346-353. A2456. interstitial pneumonia. Am J Respir Crit Care Med 2014; 190: 208-217. pilot trial. Eur Respir J 2013; 41: 853-860. fibrotic interstitial lung disease. Eur Respir J 2017; 49: 1602494. Lancet Respir Med 2017; 5: 806-815. Med 2018; 6: 759-770. lung disease. Respir Med 2012; 106: 429-435. disease: a prospective cohort study. Respir Med 2014; 108: 203-210. pulmonary fibrosis and other interstitial lung diseases. Chest 2017; 152: 982A. Rehabil Med 2019; 55: 103-112. fibrosis. Respir Care 2011; 56: 783-789. pulmonary rehabilitation. Lung 2014; 192: 367-376. 1779.

Rifaat N, Anwar E, Ali YM, et al. Value of pulmonary rehabilitation in patients with idiopathic pulmonary

Strookappe B, Elfferich M, Swigris J, et al. Benefits of physical training in patients with idiopathic or end-stage sarcoidosis-related pulmonary fibrosis: a pilot study. Sarcoidosis Vasc Diffuse Lung Dis 2015; 32: 43-52.

Jarosch I, Schneeberger T, Gloeckl R, et al. Effects of a 3-week pulmonary rehabilitation program in patients with idiopathic pulmonary fibrosis-a randomized, controlled trial. Eur Respir J 2016; 48, Suppl. 60, OA3050.

Gaunaurd IA, Gomez-Marin OW, Ramos CF, et al. Physical activity and quality of life improvements of patients with idiopathic pulmonary fibrosis completing a pulmonary rehabilitation program. Respir Care 2014; 59:

Vainshelboim B, Oliveira J, Yehoshua L, et al. Exercise training-based pulmonary rehabilitation program is clinically beneficial for idiopathic pulmonary fibrosis. Respiration 2014; 88: 378-388.

Nishiyama $\mathrm{O}$, Kondoh Y, Kimura $\mathrm{T}$, et al. Effects of pulmonary rehabilitation in patients with idiopathic

Ozalevli S, Karaali HK, Ilgin D, et al. Effect of home-based pulmonary rehabilitation in patients with idiopathic

Rammaert B, Leroy S, Cavestri B, et al. Home-based pulmonary rehabilitation in idiopathic pulmonary fibrosis.

Lindell KO, Olshansky E, Song M, et al. Impact of a disease-management program on symptom burden and health-related quality of life in patients with idiopathic pulmonary fibrosis and their care partners. Heart Lung

Horton MR, Santopietro V, Mathew L, et al. Thalidomide for the treatment of cough in idiopathic pulmonary

Jastrzebski D, Kozielski J, Zebrowska A. Pulmonary rehabilitation in patients with idiopathic pulmonary fibrosis

Holland AE, Hill CJ, Conron M, et al. Short-term improvement in exercise capacity and symptoms following

Dutta P, Funston W, Mossop H, et al. Randomised, double-blind, placebo-controlled pilot trial of omeprazole in

Zeng ZY. Recent study on traditional Chinese medicine foot bath combined with traditional Chinese and western medicine nursing for IPF. Chinese Community Doctors [zhong guo she qu yi shi] 2015; 31: 143-146.

Nolan CM, Maddocks M, Maher TM, et al. Improvement in gait speed with pulmonary rehabilitation is associated with increased survival in idiopathic pulmonary fibrosis. Am J Respir Crit Care Med 2018; 197:

Corte TJ, Keir GJ, Dimopoulos K, et al. Bosentan in pulmonary hypertension associated with fibrotic idiopathic

Hoeper MM, Halank M, Wilkens $\mathrm{H}$, et al. Riociguat for interstitial lung disease and pulmonary hypertension: a

Schaeffer MR, Ryerson CJ, Ramsook AH, et al. Effects of hyperoxia on dyspnoea and exercise endurance in

Nathan S, Behr J, Collard HR, et al. RISE-IIP: riociguat for the treatment of pulmonary hypertension associated with idiopathic interstitial pneumonia. Eur Respir J 2017; 50: Suppl. 61, OA1985.

Birring SS, Wijsenbeek MS, Agrawal S, et al. A novel formulation of inhaled sodium cromoglicate (PA101) in idiopathic pulmonary fibrosis and chronic cough: a randomised, double-blind, proof-of-concept, phase 2 trial.

Visca D, Mori L, Tsipouri V, et al. Effect of ambulatory oxygen on quality of life for patients with fibrotic lung disease (AmbOx): a prospective, open-label, mixed-method, crossover randomised controlled trial. Lancet Respir

Rastogi SA, Koltharkar M, Udwadia ZF. Prospective study of pulmonary rehabilitation in interstitial lung disease in resource limited setting: An Indian experience. Am J Respir Crit Care Med 2015; 191: A2020.

Ryerson CJ, Cayou C, Topp F, et al. Pulmonary rehabilitation improves long-term outcomes in interstitial lung

Del Castillo NT, Paredes L, Shek N, et al. Benefits of pulmonary rehabilitation in patients with idiopathic

Chehere B, Bougault V, Chenivesse C, et al. Cardiorespiratory adaptation during 6-minute walk test in fibrotic idiopathic interstitial pneumonia patients who did or did not respond to pulmonary rehabilitation. Eur J Phys

Nolan CM, Maddocks M, Delogu V, et al. Responsiveness and minimum clinically important difference (MCID) of the 4-metre gait speed (4MGS) in fibrotic interstitial lung disease. Am J Respir Crit Care Med 2017; 195: A4291. Keyser RE, Woolstenhulme JG, Chin LM, et al. Cardiorespiratory function before and after aerobic exercise training in patients with interstitial lung disease. J Cardiopulm Rehabil Prev 2015; 35: 47-55.

Swigris JJ, Fairclough DL, Morrison M, et al. Benefits of pulmonary rehabilitation in idiopathic pulmonary

Jackson RM, Gomez-Marin OW, Ramos CF, et al. Exercise limitation in IPF patients: a randomized trial of

Keir G, Corte T, Parfitt L, et al. Bosentan in pulmonary hypertension associated with fibrotic idiopathic interstitial pneumonia: A randomized, double-blind, placebo-controlled study. Eur Respir J 2013; 42, Suppl. 57,

ambulatory oxygen on health status in patients with fibrotic interstitial lung disease. Am J Respin Crit Carects of 2017; 195: A7603. 

Rehabil Med 2019; 55: 103-112.

64 Dowman L, McDonald CF, Hill C, et al. The benefits of exercise training in interstitial lung disease: protocol for a multicentre randomised controlled trial. BMC Pulm Med 2013; 13: 8.

65 Dowman L, McDonald C, Hill C, et al. Effect of disease aetiology on response to exercise training in patients with interstitial lung disease. Respirology 2015; 20: 58 .

66 Dowman LM, McDonald CF, Hill CJ, et al. Effect of disease aetiology on response to exercise training in patients with interstitial lung disease. Am J Respir Crit Care Med 2015; 191: A2460.

67 Jarosch I, Schneeberger T, Gloeckl R, et al. Different effects of pulmonary rehabilitation in anxious vs. nonanxious patients with idiopathic pulmonary fibrosis - a pilot study. Am J Respir Crit Care Med 2017; 195 : A4279. Schneeberger T, Glockl R, Jarosch I, et al. Effects of a 3-week inpatient pulmonary rehabilitation in patients with idiopathic pulmonary fibrosis - a randomized, controlled trial. Wien Klin Wochenschr 2016; 128: 779-780. Keyser RE, Christensen EJ, Chin LM, et al. Changes in fatigability following intense aerobic exercise training in patients with interstitial lung disease. Respir Med 2015; 109: 517-525.

Jackson R, Ramos C, Cardenas D, et al. Effects of aerobic and strength training on symptoms and exercise capacity of IPF patients. Eur Respir J 2012; 40: Suppl. 56, P3686.

a nard IA, Cardenas DD, Cahalin LP, et al. Health-related quality of life of IPF patients in a pulmonary rehabilitation program (Abstract). Am J Respir Crit Care Med 2014; 189: A2639.

72 Gomez O, Ramos CF, Cardenas D, et al. Exercise training during pulmonary rehabilitation increases activity levels of IPF patients. Am J Respir Crit Care Med 2012; 185: A4885.

73 Rifaat N, Anwar E, Ali YM, et al. Value of pulmonary rehabilitation in patients with idiopathic pulmonary fibrosis. Eur Respir J 2014; 44: Suppl. 58, P3692.

74 Ryerson CJ, Cayou C, Topp F, et al. Pulmonary rehabilitation improves long-term quality of life in patients with interstitial lung disease. Am J Respir Crit Care Med 2013; 187: A5955.

75 Ryerson CJ, Cayou C, Topp FJ, et al. Pulmonary rehabilitation in interstitial lung disease: Predictors of success. Am J Respir Crit Care Med 2012; 185: A6853.

76 Ryerson CJ, Topp F, Cayou C, et al. A low baseline 6mwd predicts greater improvement from pulmonary rehabilitation in interstitial lung disease. Am J Respir Crit Care Med 2013; 187: A5956.

77 Vainshelboim B, Oliveira J, Fox B, et al. Effect of exercise pulmonary rehabilitation on long-term outcomes in idiopathic pulmonary fibrosis. Eur Respir J 2014; 66; Suppl. 58, A3644.

78 Vainshelboim B, Oliveira J, Fox BD, et al. Effect of exercise pulmonary rehabilitation on long-term outcomes in idiopathic pulmonary fibrosis. Eur Respir J 2014; 44: Suppl. 58, P602.

79 Vainshelboim B, Oliveira J, Yohoshua L, et al. Effect of pulmonary rehabilitation program on exercise tolerance and functional capacity in patients with idiopathic pulmonary fibrosis. Med Sci Sports Exerc 2013; 45: 543-543.

80 Vainshelboim B, Oliveira J, Fox BD, et al. Long-term effects of a 12-week exercise training program on clinical outcomes in idiopathic pulmonary fibrosis. Lung 2015; 193: 345-354.

81 Vainshelboim B, Fox BD, Kramer MR, et al. Short-term improvement in physical activity and body composition after supervised exercise training program in idiopathic pulmonary fibrosis. Arch Phys Med Rehabil 2016; 97: 788-797.

82 Vainshelboim B, Kramer MR, Fox BD, et al. Supervised exercise training improves exercise cardiovascular function in idiopathic pulmonary fibrosis. Eur J Phys Rehabil Med 2016; 53: 209-218.

83 Holland AE, Hill CJ, Glaspole I, et al. Benefits of exercise training are related to disease severity in idiopathic pulmonary fibrosis. Am J Respir Crit Care Med 2011; 183: A1522.

84 Kozu R, Senjyu H, Jenkins SC, et al. Differences in response to pulmonary rehabilitation in idiopathic pulmonary fibrosis and chronic obstructive pulmonary disease. Respiration 2011; 81: 196-205.

85 Van Manen M, Van't Spijker A, Tak N, et al. Patient and partner 'empowerment' program in idiopathic pulmonary fibrosis (PPEPP): Improving quality of life in patients and their partners. QJM 2016; 109 : S46.

86 Borg GA. Psychophysical bases of perceived exertion. Med Sci Sports Exerc 1982; 14: 377-381.

87 Jones PW, Quirk FH, Baveystock CM, et al. A self-complete measure of health status for chronic airflow limitation. The St. George's Respiratory Questionnaire. Am Rev Respir Dis 1992; 145: 1321-1327.

88 Guyatt GH, Berman LB, Townsend M, et al. A measure of quality of life for clinical trials in chronic lung disease. Thorax 1987; 42: 773-778.

89 McGavin CR, Artvinli M, Naoe H, et al. Dyspnoea, disability, and distance walked: comparison of estimates of exercise performance in respiratory disease. $\mathrm{Br}$ Med J 1978; 2: 241-243.

90 Mahler DA, Weinberg DH, Wells CK, et al. The measurement of dyspnea. Contents, interobserver agreement, and physiologic correlates of two new clinical indexes. Chest 1984; 85: 751-758.

91 Medical Research Council. Standardized questionnaires on respiratory symptoms. Br Med J 1960; 2 : 1665.

92 Eakin EG, Resnikoff PM, Prewitt LM, et al. Validation of a new dyspnea measure: the UCSD shortness of breath questionnaire. Chest 1998; 113: 619-624.

93 Hanada M, Sakamoto N, Ishimatsu Y, et al. Effect of long-term treatment with corticosteroids on skeletal muscle strength, functional exercise capacity and health status in patients with interstitial lung disease. Respirology 2016; 21: $1088-1093$.

94 Currow DC, McDonald C, Oaten S, et al. Once-daily opioids for chronic dyspnea: a dose increment and pharmacovigilance study. J Pain Symptom Manage 2011; 42: 388-399.

95 Bradley B, Branley HM, Egan JJ, et al. Interstitial lung disease guideline: the British Thoracic Society in collaboration with the Thoracic Society of Australia and New Zealand and the Irish Thoracic Society. Thorax 2008; 63: Suppl 5, v1-58.

96 Faisal A, Alghamdi BJ, Ciavaglia CE, et al. Common mechanisms of dyspnea in chronic interstitial and obstructive lung disorders. Am J Respir Crit Care Med 2016; 193: 299-309.

97 Ekström MP, Bornefalk-Hermansson A, Abernethy AP, et al. Safety of benzodiazepines and opioids in very severe respiratory disease: national prospective study. BMJ 2014; 348: g445.

98 Bajwah S, Davies JM, Tanash H, et al. Safety of benzodiazepines and opioids in interstitial lung disease: a national prospective study. Eur Respir J 2018; 52: 1801278. 
O'Driscoll BR, Howard LS, Earis J, et al. BTS guideline for oxygen use in adults in healthcare and emergency settings. Thorax 2017; 72: ii1-ii90.

100 Lacasse Y, Martin S, Lasserson T, et al. Meta-analysis of respiratory rehabilitation in chronic obstructive pulmonary disease. A Cochrane systematic review. Eura Medicophys 2007; 43: 475-485.

101 Brighton LJ, Miller S, Farquhar M, et al. Holistic services for people with advanced disease and chronic breathlessness: a systematic review and meta-analysis. Thorax 2019; 74: 270-281.

102 Similowski T, Serresse L. Lessons from negative dyspnoea studies: arguments for the multidimensional evaluation of multidirectional therapeutic approaches. Eur Respir J 2019; 53: 1802471.

103 Bausewein C, Farquhar M, Booth S, et al. Measurement of breathlessness in advanced disease: a systematic review. Respir Med 2007; 101: 399-410. 